\title{
Planning and Urban Ecology: A New Elective in City and Regional Planning
}

Adrienne Greve, Corbin Johnson, and KeVIn Waldron

Adrienne Greve, Ph.D. is assistant professor at Cal Poly's City and

Regional Planning Department. Corbin Johnson and Kevin Wladron are seniors in the BSCRP program.

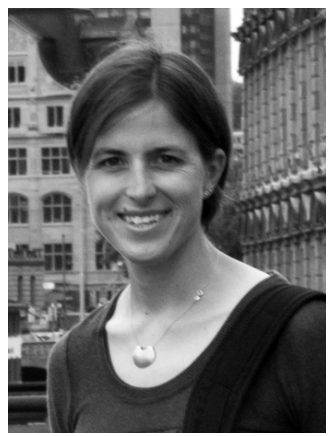

Figure 1 Poly Calyon Village, under construction. Photo by A. Greve.
Since recently joining the CRP department, Adrienne Greve has been using her background in the sciences to strenghenthen the relationship between the fields of planning and urban ecology with a particular emphasis on water systems. In this article, together with seniors Corbin Johnson and Kevin Waldron, she writes about her new elective and an important class project, which is monitoring the impacts of the new campus housing on the campus creek system.

In an urban area or human-dominated setting, ecological systems such as creeks become places where human and biophysical processes not only coexist, but directly interact and influence each other. Urban Ecology is a fairly new field of study that integrates the social sciences, natural sciences, and humanities (Alberti et al 2003). Urban Ecology provides a conceptual framework to understand the interaction of human systems (e.g. social, built, economic, etc.) and biophysical processes. If a system is understood to be comprised of both human and biophysical processes, any study of this system must assess both. During the spring quarter of 2007, a group of CRP students devised a monitoring system to do just that as part of a new course, Planning and Urban Ecology. The focus of the study was Brizzolara Creek located on the Cal Poly campus. In an effort to understand both the ecological and social long-term impacts of the new LEED-certified student housing (Poly Canyon Village, PVC) being built along the creek, students designed a monitoring program and collected ecological and social data. The data collection included stream channel morphology measurement and social surveys.

\section{Monitoring Program Design}

The goal of the monitoring program was to track long-term changes in stream channel morphology as it responds to land use change in its contributing watershed and to understand the evolving role of Brizzolara Creek on the Cal Poly campus as 2,700 students move in along its banks. Documenting these changes will provide data needed to inform management strategies to maintain key functions of the creek including ecological, social, cultural, and economic. We targeted seven points on the creek most likely to be affected by land use changes, particularly those associated with PCV (Fig.1). The Cal Poly community, defined as students, faculty, staff, and community members, was targeted to assess the social role of Brizzolara Creek through surveys. These data coupled with subsequent data collection in the future will allow better understanding of the

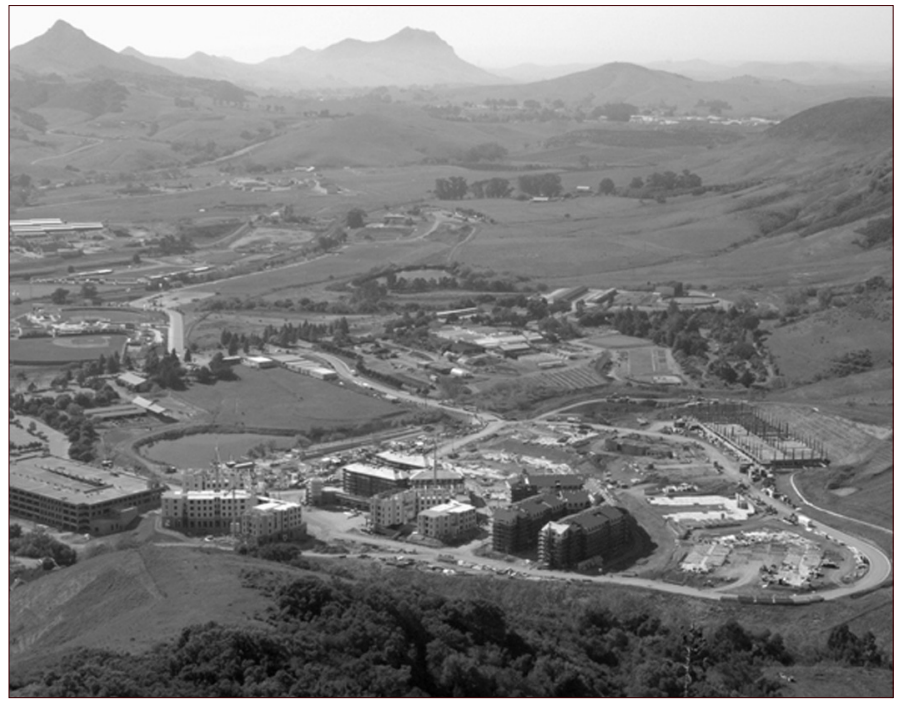

creek's response to land use changes and its role on campus.

Nine research questions were identified. Research questions were divided into three groups: stream channel morphology, social perception and knowledge, and interaction.

Stream channel morphology:

1. Does channel morphology and/or streambed substrate size distribution respond to management decisions (including restoration and mitigation) and changes in land cover (current and future construction)? Particularly:

- Poly Canyon Village changes in land cover and runoff routing

- Bridge construction and replacement

Social survey research questions:

2. What is the awareness and perception of Brizzolara Creek in the Cal Poly community? 
3. How are the areas along Brizzolara Creek used? Who is using these areas?

4. What are the most valued and least valued aspects of Brizzolara Creek and associated areas?

5. What are the 'cues' informing perceptions of health?

6. What types of change does the Cal Poly community desire?

7. Will awareness and perceptions of Brizzolara Creek change with the new construction near the creek (for example, Poly Canyon Village and Engineering buildings)?

Interaction questions:

8. Are shifts in social perception and awareness related to shifts in channel condition?

9. Do management decisions influence both social awareness and ecological condition?

\section{Data Collection Methods}

A total of seven sites were selected on Brizzolara creek for stream channel measurement and characterization. The purpose of these sites was to document conditions and trends in channel morphology, bed substrate composition, and other physical parameters. Methods were adapted from the US Geological Survey and California Department of Fish and Game (Fitzpatrick et al 1998, Flosi et al 1998).

The social survey was used to satisfy our goals of understanding the role or Brizzolara Creek in the Cal Poly community. The survey was broken into three parts: demographics, usership, and perception and knowledge. The following is a list of the open ended questions:

- Do you view Brizzolara Creek as healthy? On what do you base your assessment?

- What do you see as potential threats to the health of the creek?

-What do you value about the creek?

- What do you value least about the creek?

- If you could add/change anything about Brizzolara Creek, what would it be?

- How do you think Brizzolara Creek contributes to campus life?

- Is there anything else you would like to share?

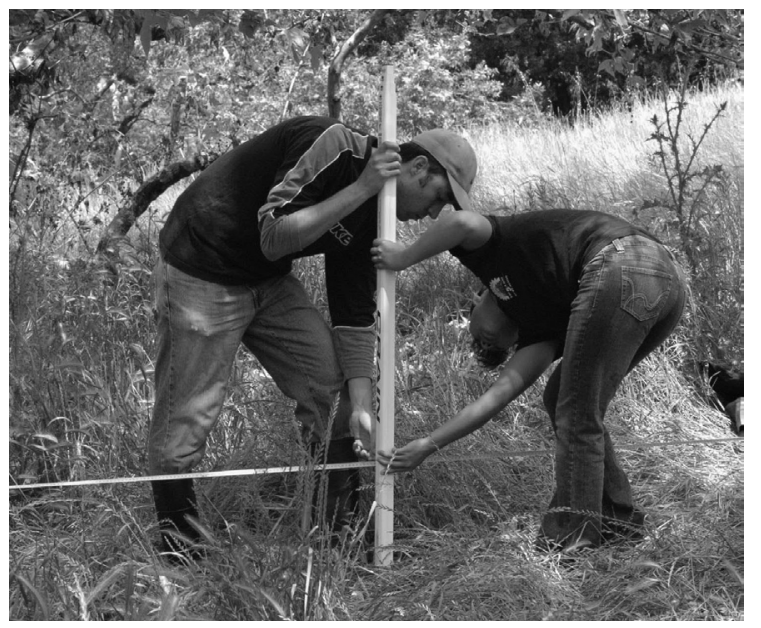

\section{Figure 3}

Mike and Emma, and field method 2: cross section. Photo by $A$. Greve.

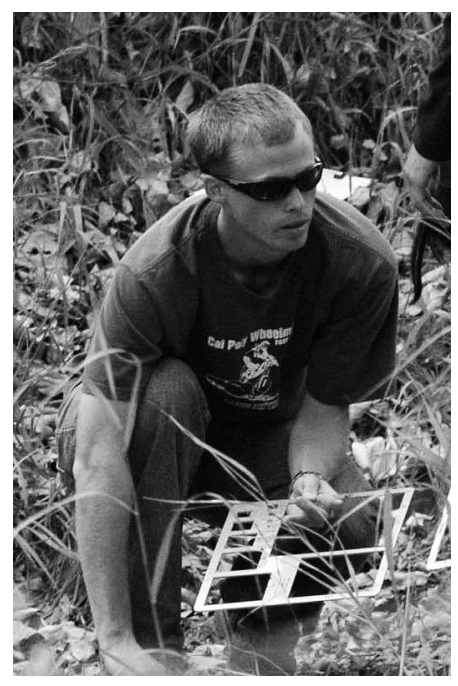

\section{Figure 2}

Corbin and field method 1: pebble count.

Photo by A. Greve.

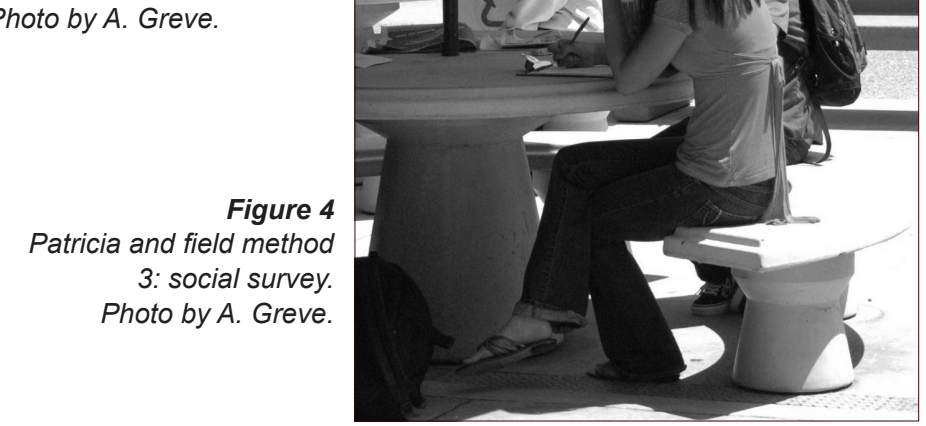




\section{Channel Morphology Results}

Brizzolara Creek progresses from an environment with less development in the adjacent riparian areas to a more developed, urban environment, where the shape of the channel changes drastically. At the uppermost site (010, Fig.5), the channel is wide and relatively shallow compared to farther downstream cross-sections. The width and shallow depth illustrate a channel that has room to migrate and utilize its associated flood plain during high flows. As one moves downstream, the channel is noticeably more incised and narrow as it is confined to a narrow path dictated by surrounding development.

Brizzolara Creek serves as spawning habitat for the threatened steelhead trout in high flow years. Substrate size distributions were evaluated based on the pebble-sized classes that provide spawning habitat. The majority of the pebble count data revealed unsuitable habitat for spawning steelhead trout, however, pebble counts immediately adjacent to PCV appeared to be most suitable, with the majority of the pebble count data falling within the specified range (Fig. 6). If change were to occur in the stream bed substrate distribution due to the new housing it will likely be apparent in future pebble counts and cross sections in these areas. A potential substrate change in these areas, specifically a finer sediment load deposition, commonly associated with runoff from developed environments, could result in the loss or change of viable steelhead habitat.

\section{Social Survey Results}

231 social surveys were collected and, based on a comparison to campus demographics, were viewed as representative of the campus community. Save for the initial demographic questions, the survey questions were open-ended. Prior to analysis, all responses were categorized into themes.

\section{Figure 5}

Channel cross section results. The sites are numbered from upstream to downstream, 010 to

070. The creek channel begins having access

to its floodplain and becomes increasingly channelized as it moves through main campus.

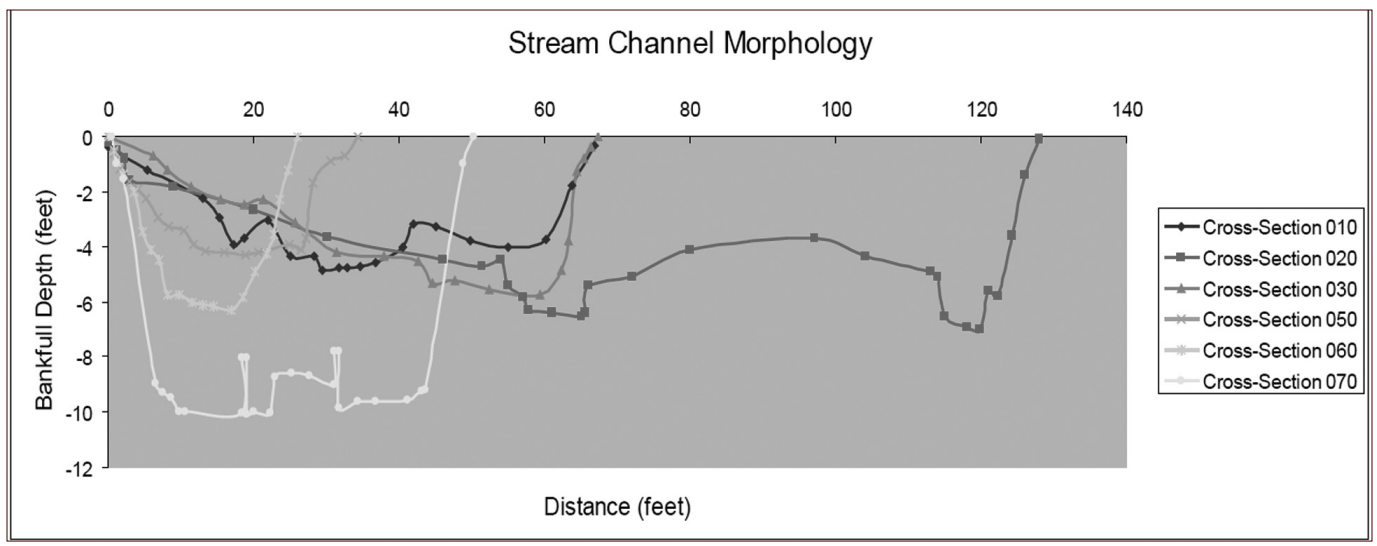

Figure 6

Pebble count data. Site 030 is located immediately adjacent to Poly Canyon Village. The shaded area is the size range identified as appropriate to support spawning steelhead trout

(National Resources

Conservation Service 2000)

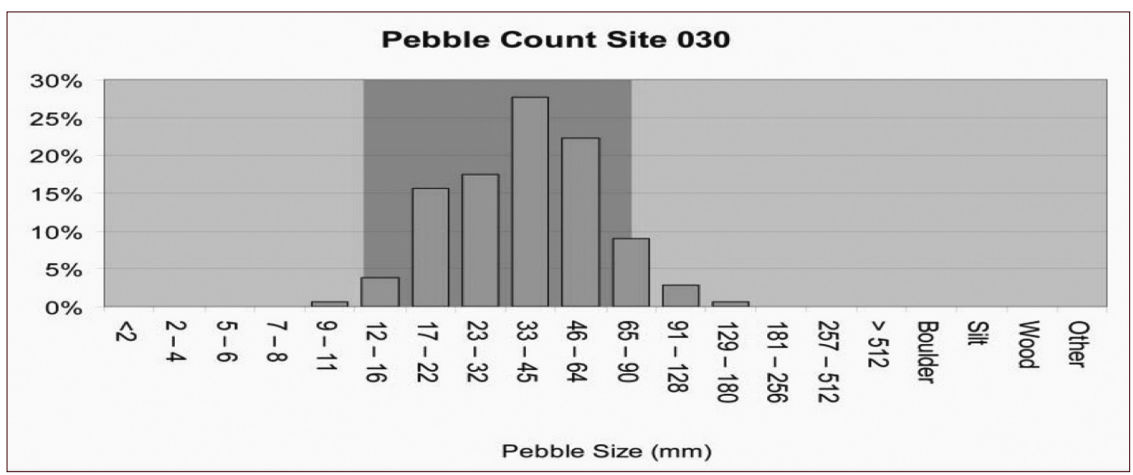


The social surveys sought to identify not only how the areas associated with the creek were used, but how the community viewed the creek. Most surprising was the result that nearly $25 \%$ of survey respondents were unaware that there was a creek on campus. The percentage grew to nearly $40 \%$ if confined to respondents who had been on campus for one year or less, indicating a need to build awareness. From the questions addressing perceptions of the creek, one of the recurring was a strong sense of a need for change, but little agreement on what the changes needed. Only $40 \%$ of respondents viewed the creek as healthy and nearly $80 \%$ expressed a desire for change. However, when asked what should be changed, no response was mentioned by more than $25 \%$ of respondents, and this change was a desire for increased water levels. The association between the presence of water and creek health may indicate a lack of awareness about creek function in arid and semi-arid climates, where creeks are expected to go dry during part of the year. Many students on the Cal Poly campus come from moist climates. When asked what was most valued about the creek, respondents overwhelmingly valued the Brizzolara Creek Area as an aesthetic resource.

\section{Future Management Recommendations}

While the channel morphology data will require several years of study to clearly indicate trends, the social survey results can be acted on immediately to affect positive change. The surveys identified a general lack of campus awareness concerning Brizzolara Creek. Because of this, our recommendation for future management of the creek is to focus on education and promoting usership. We believe that environmental stewardship can form from general awareness on campus. To help achieve this awareness, we propose the implementation of informational placards, creek art, and increased physical interaction with the creek on campus through clubs, the Week of Welcome (WOW), and campus tours.

- Placards promoting environmental awareness: As reflected in our survey results, the longer a student has been on campus directly correlates with their awareness of Brizzolara Creek's existence. In order to shorten the time it takes to become aware, we propose several, highly visible awareness placards be placed in areas with high volumes of foot traffic. This is particularly important in coming years as PCV fills with thousands of new students, increasing the access and visibility of the creek.

- Creek Art: Creek art can create an ambiance--drawing people to recreate or relax--along the creek. It should not be limited to sculptures, tiles, or benches; rather, it should be incorporated into the very structure of bridges spanning the creek. The current Via Carta Bridge and downstream pedestrian crossing bridge fail to integrate visual appeal into their structural designs.

- University Programs: An integral part of creating a successful management program for Brizzolara Creek includes involving a wide array of people across campus. We would like to see Week of Welcome (WOW), Associated Students Incorporated (ASI), and environmental clubs take an active interest in programs for the creek. Each of these organizations could potentially educate students in urban ecology and create more environmental awareness across the campus. According to our surveys, approximately $25 \%$ of the campus is unaware of the Brizzolara Creek system. One potential awareness-raising activity would be a creek clean-up day that would satisfy our main goal of establishing campus-wide ecological citizenship. This would entail a once-a-year clean up, promoting outside community and student volunteers to help maintain Brizzolara.

\section{Students Taking the Work One Step Further}

Utilizing their experiences in the course Planning and Urban Ecology, five City and Regional Planning undergraduates have been compelled to use their senior projects as a means to enact positive change for both the physical and social health of Brizzolara Creek. Teaming theoretical knowledge with science, these projects dissolve the barrier between theory and practice by not merely identifying a problem, but providing sound solutions and implementing them. 
Fifth-year BSCRP student, Erin Belfils seeks to bring change along the banks of Brizzolara Creek within a short timeframe. Erin is concentrating her efforts on the "H2" staff parking lot that abuts Brizzolara at the intersection of Highland Drive and Via Carta Road. Stormwater runoff and the associated pollution generated from this parking lot are piped directly into the creek. Erin's project will consist of a redesign of this lot using many Low Impact Development (LID) principles to improve water quality and the utility of the site for both parking and pedestrians. Along with proposing design ideas and principles to help clean up and reduce the stormwater impact from the lot, Erin has included the redevelopment of part of this lot into a park into her design. During the preliminary stages of her project, Erin was alerted that the parking lot she chose to redevelop is slated to be removed for riparian habitat restoration about ten years down the road. Erin is continuing on with the project with the support of campus decision makers; after all, ten years of runoff control and reduced pollution otherwise dumped into Brizzolara Creek is well worth the time.

Similar to Erin's project, but on a much larger scale, fourth-year BSCRP student, Melissa Cole is working to redesign the "H12" student and staff parking lot. Located along a substantial portion of the north bank of Brizzolara Creek, this parking lot slopes downhill towards the creek and surface runoff is routed directly into the creek via culverts. Running underneath her project site are two culverts routing additional storm water to Brizzolara from parking lots and infrastructure further uphill. Similar to Erin, Melissa is also seeking to use LID practices to reduce the amount of runoff entering the creek and filter out pollutants. A fiscal and feasibility analysis will also be integrated into her project. The H12 parking lot is full of challenges for Melissa to conquer, including issues of slope, layout and design, and the need to keep the same number of available parking spaces.

While the two parking lot LID design proposals are geared more towards immediate implementation and construction goals, fourth-year BSCRP students, Corbin Johnson and Doug McIntyre's project consists of both short-term and long-term plans concerning Brizzolara Creek. East Creek Road, an eroding dirt service road runs along the north bank of Brizzolara from Via Carta Road on the east to the intersection of Highland Drive and California Boulevard on the west. Corbin and Doug aim to produce a plan to revitalize East Creek Road into a multiuse pathway to serve as an educational and travel corridor complete with benches, ponder points, educational placards, and increased riparian habitat plantings. The intersection of Highland Drive, California Boulevard, and East Creek Road is a major focal point to one of the most used entrances to Cal Poly, so considerable effort will be spent to produce a plan that will improve the aesthetics in that particular area which will show off Cal Poly's pride and care it shows for its campus and community. This portion of their project will be designed to be implemented in the near future.

Parallel, but on the opposite bank of East Creek Road, are two small parking lots (one of which is Erin Belfil's study area) and a pathway within the riparian vegetation that connects the two. Seeing the existing pathway as a valuable asset to the community, and the pending removal of the two parking lots, Corbin and Doug will produce long range plans that address what may be suitably located in these areas in ten or so years when the space is available for revitalization. Possibilities include a park-like setting with social interaction, reflection, and outdoor classroom learning opportunities. Corbin and Doug plan to use natural and sustainable materials that are durable and fit in with the environment, and landscape with native plants that require low levels of maintenance, upkeep, and watering.

As Erin, Melissa, Doug, and Corbin focused primarily on the physical attributes of Brizzolara Creek, another project specifically hones in on the social components of Brizzolara Creek, citing awareness as the major opportunity for growth. This project aims to utilize Brizzolara Creek to expand the learning experience beyond the confines of the classroom. The project goals include building a stronger community, promoting awareness, and facilitating participation. These are all seen as components of broad-based environmental stewardship. Creating an atmosphere where stewardship can flourish requires direction, goals, and foresight. To fill this need, Kevin Waldron, a fifth-year BSCRP, is developing the Brizzolara Creek Outreach Program. First, Kevin identified goals bridging multiple disciplines. This resulted in the creation of the Brizzolara Creek Coalition, comprised of student groups, staff, and community leaders. The coalition is the critical element 
in sustaining the broader outreach program. Moreover, this coalition is expected to grow as PCV exposes the new residents to the creek as never before. PCV presents a great opportunity, an opportunity to educate students on their local environments, giving them a greater understanding of environments worldwide. In an effort to build awareness beyond those living in PCV, Kevin aims to accomplish the creation of the first "Cal Poly Creek Day" scheduled early May 2008. Creek Day celebrates the value of Brizzolara Creek in our growing campus life through an array of activities ranging from restoration projects to educational booths. These activities aim to empower people to take ownership of an ecosystem they may have never understood how they and their peers affect, an ecosystem that relies heavily on the protection of us and society. The protection of Brizzolara Creek is, in fact, in our hands. Creek Day recognizes this and pronounces it to the Cal Poly and San Luis Obispo communities through restoration and maintenance activities.

Through restoration and maintenance activities, Creek Day acts as a forum for public participation, enticing active participation across multiple disciplines and interests to help clean the creek. Trash collection efforts, tree plantings, trail maintenance, vegetation restoration, creek bed enhancement and other necessities for Brizzolara Creek are implemented in order to promote the healthy existence of biophysical processes in an urban dominated setting.

Ultimately, the outreach program teamed with parking and creek pathway designs act as an agent for change to provide an ever-growing community an opportunity to build a healthier creek and a more informed public. Thanks to five Cal Poly students, this agent for change is reality and is empowering people to realize a better quality of life and environment.

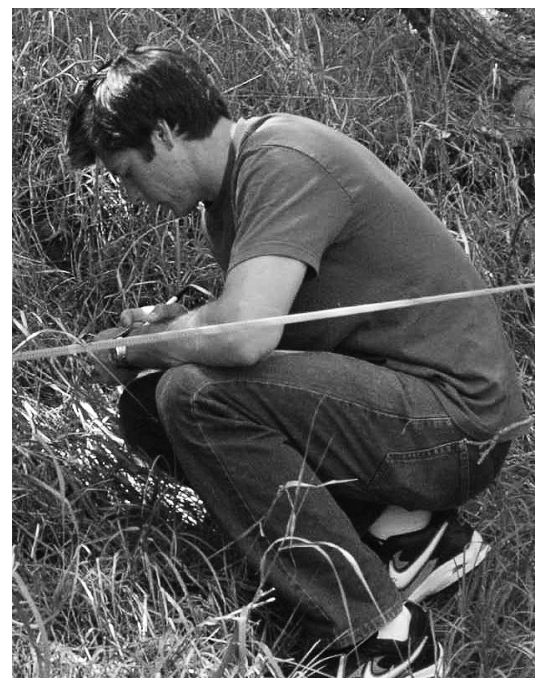

Figure 7

Kevin during field work. He is one of the students in this class who continued to develop the work in his senior project. 